\title{
Ofrendas en el humedal: el santuario ibero de Haza del Rayo (Sabiote, Jaén)*
}

\section{Offerings in the wetland: the Iberian sanctuary of Haza del Rayo (Sabiote, Jaén)}

\author{
Carmen Rueda Galána , Juan P. Bellón Ruiza , Ana B. Herranz Sánchez, \\ Miguel A. Lechuga Chica ${ }^{a}$, Arturo Ruiz Rodríguez ${ }^{\mathrm{a}}$, M. ${ }^{\mathrm{a}}$ Isabel Moreno Padilla ${ }^{\mathrm{a}}$, \\ Manuel Molinos Molinos ${ }^{\mathrm{a}}$, Carmen Rísquez Cuenca ${ }^{\mathrm{a}}$, Mario Gutiérrez Rodríguez ${ }^{\mathrm{b}}$ y \\ Marta Portilloc
}

\section{RESUMEN}

Damos a conocer el hallazgo de un santuario ibero, situado en la Loma de Úbeda (Jaén), en un punto clave de conexión entre los valles del Guadalquivir y del Guadalimar, definido como un espacio al aire libre, al que se asocia un depósito votivo del siglo III a. n. e. El interés de este estudio de caso radica en la aplicación de un protocolo fuertemente interdisciplinar, que parte de excavaciones arqueológicas, microprospecciones magnéticas sistemáticas y análisis combinados (micromorfología de suelos, análisis de polen y fitolitos, dataciones, estudios geo-radar 3D y análisis metalográficos). Este protocolo ha permitido documentar la dinámica ritual que involucra a una pequeña área de paleo-humedal, así como su caracterización general. Este espacio, definido como un punto clave en el itinerario ritual que parte de la ciudad de Baecula (Santo Tomé, Jaén) y se dirige al santuario de la Cueva de la Lobera en Castellar (Jaén), nos sitúa ante la complejidad de los paisajes religiosos en un territorio como el de Cástulo (Linares, Jaén) para los siglos IV-III a. n. e., en los que cobra importancia la incorporación de hitos naturales con significados culturales muy específicos.

\begin{abstract}
We present a new Iberian sanctuary situated on the hill known as La Loma de Úbeda (Jaén), located at a key connecting point between the Guadalquivir and Guadalimar valleys. It is an open-air site with a $3^{\text {rd }}$ century $B C E$ votive deposit. A large part of the interest in this case study lies in the application of a strongly interdisciplinary protocol which combines archaeological excavations, systematic magnetic micro-surveying and combined analyses (soil micromorphology, pollen and phytolith analyses, OSL datings, $3 D$ groundpenetrating radar studies and metallographic analysis). This protocol has made it possible to document the ritual dynamics involving this small area of paleo-wetland. The site is placed at a key point on the ritual itinerary between the town of Baecula (Santo Tomé, Jaén) and the sanctuary of La Cueva de la Lobera in Castellar (Jaén). The present study reveals the complexity of the religious landscapes in a territory similar to that of Cástulo (Linares, Jaén) in the $4^{\text {th }}$ and $3^{\text {rd }}$ centuries $B C E$, in which the natural landmarks with strong specific cultural significances played an important role.
\end{abstract}

* Esta intervención y los análisis desarrollados han contado con la financiación del Instituto Universitario de Arqueología Ibérica (Universidad de Jaén) y del Ministerio de Fomento, a través de la empresa Peninsular de Contratas, S.A. y UTE Villacarrillo (Dirección de Obra: José Lorente Gutiérrez). También se ha contado con el soporte económico de la Ayuda Complementaria del Subprograma Ramón y Cajal, Ministerio de Ciencia e Innovación (RYC 2017-22122).

a Instituto Universitario de Investigación en Arqueología Ibérica, Universidad de Jaén. Campus Las Lagunillas s/n. 23071 Jaén. Correos e.: CRG caruegal@ujaen.es https://orcid.org/0000-0003-2531-7197; JPBR jbellon@ujaen.es https://orcid.org/0000-0002-2192-8874; ABHS aherranz@ujaen.es https://orcid.org/0000-0001-9160-3584; MALC mlechuga@ujaen.es https://orcid.org/0000-0002-2759-2275; ARR arruiz@ujaen.es https://orcid.org/0000-0002-7992-872X; MIMP imoreno@ujaen.es https://orcid.org/0000-0002-7894-7136; MMM mmolinos@ujaen.es https://orcid.org/0000-0001-7396-9718; CRC crisquez@ujaen.es https://orcid.org/0000-0002-3888-2972

b Dpto. de Prehistoria y Arqueología, Facultad de Filosofía y Letras. Universidad de Granada. Campus Universitario de Cartuja s/n. 18071 Granada. Correo e.: mgrodrig@ujaen.es https://orcid.org/0000-0003-2045-1493

Dpto. de Arqueología y Antropología, Arqueología de las Dinámicas Sociales (2017SGR 995). Institució Milà i Fontanals. Consejo Superior de Investigaciones Científicas (CSIC).08001 Barcelona. Correo e.: mportillo@imf.csic.es https://orcid.org/0000-0002-2703-031X

Recibido 18-X-2020; aceptado 10-XII-2020.

Copyright: (C) 2021 CSIC. Este es un artículo de acceso abierto distribuido bajo los términos de la licencia de uso y distribución "Creative Commons Reconocimiento 4.0 Internacional" (CC BY 4.0) 
Palabras clave: santuario ibero; paleo-humedal; Andalucía; siglos IV-III a. n. e.; movilidad ritual; ortofotografía de alta resolución; microprospección magnética; análisis geoarqueológicos; análisis de fitolitos.

Key words: Iberian sanctuary; paleo-wetland; Andalucia; $4^{\text {th }}-3^{\text {rd }}$ centuries $B C E$; ritual mobility; high-resolution digital orthophotograph; magnetic micro-surveying; geoarchaeological analysis; phytolith analysis.

\section{INTRODUCCIÓN}

Esta investigación parte de la formalización de varias denuncias de expolio que localizaban exvotos de bronce ibéricos en la zona denominada como Haza del Rayo (Sabiote, Jaén) del trazado de la nueva autovía A32. Los trabajos previos del impacto arqueológico de esta infraestructura habían ubicado una dispersión de material ibérico, sin indicadores iniciales que permitiesen caracterizarlo como un lugar de culto ${ }^{1}$. Precisamente el rastreo del trazado de la autovía en construcción, por parte de los expoliadores, fue el detonante de la denuncia y del inicio de una actividad urgente que paralizase el expolio y permitiese investigar el sitio ${ }^{2}$. Esta coyuntura ofrecía una oportunidad para abordar de manera sistemática el estudio y caracterización de este nuevo espacio de culto ibero.

\section{APROXIMACIÓN INTERDISCIPLINAR A LA PRÁCTICA RITUAL: EL CASO DE HAZA DEL RAYO}

El hallazgo de evidencias de un depósito de ofrendas en la divisoria de aguas de la Loma de Úbeda respondía a los patrones de localización de un espacio de culto. Se trata de un punto estratégico de conexión entre los valles del Guadalimar y Guadalquivir, que pone en relación espacios clave para el territorio en esta época, como el del santuario de la Cueva de la Lobera (Castellar) (Nicolini et al. 2004; Rísquez et al. 2018) o Baecula (Úbeda-Villacarrillo) (Bellón et al. 2015) (Fig. 1). Este nuevo espacio era uno de los pocos casos donde era posible un análisis contextual de depósitos con exvotos dado que sus antecedentes conocidos, el citado santuario de Castellar y el de Collado de los Jardines (Santa Elena), fueron sistemáticamente expoliados desde inicios del siglo XX (Rueda 2011).

\footnotetext{
1 Memoria final de la Prospección Arqueológica Superficial y propuesta de medidas correctoras, bajo la dirección de Juan Luis Herce (2016). Delegación Territorial de la Consejería de Cultura en Jaén.

${ }^{2}$ Al mismo tiempo el Servicio de Protección de la Naturaleza de la Guardia Civil iniciaba las diligencias oportunas para abrir una investigación, destinada al seguimiento de las actividades ilegales producidas.
}

Las actuaciones desarrolladas en Haza del Rayo se han planificado desde la lógica de la dinámica histórica del sitio arqueológico, evolucionando y adaptándose a sus especificidades (Fig. 2). Desde el planteamiento de la intervención el diálogo entre el registro y la propia naturaleza del lugar ha sido constante, dada su novedad respecto a los modelos conocidos. Nuestro posicionamiento metodológico parte de valorar la transcendencia de la materialidad de las prácticas rituales, proponiendo una perspectiva interdisciplinar que nos ayude a superar la mirada convencional (Grau y Rueda 2018: 49) mediante protocolos combinados, que proporcionen lecturas de carácter holístico del registro ritual (Livarda et al. 2018).

La primera fase de aproximación estuvo enfocada a la documentación del daño producido y a la definición del sitio. Comenzó por la elaboración de un modelo digital del terreno y una ortofotografía de alta resolución mediante vuelo fotogramétrico con dron. Su objetivo era generar una documentación con una elevada calidad cartográfica, que sirviera de base para las distintas actuaciones y como eje fundamental para la construcción de un Sistema de Información Geográfica específico. El alcance del daño producido en los expolios se estableció mediante georreferenciación con un Sistema de Posicionamiento Global (GPS por su sigla en inglés) de alta precisión (Leica CS 25). El mapa general resultante mostraba que las densidades de las fosas de expolio y de los hallazgos coincidían, pareciendo indiscutible que el sitio estaba desplazado hacia el noreste, es decir, hacia el paso natural que conecta los valles del Guadalimar y Guadalquivir.

Además, se desarrolló una prospección magnética en modo gradiente vertical seguida de otra con radar de subsuelo en modalidad 3D para localizar potenciales estructuras, fosas subterráneas o acumulaciones de material metálico (depósitos votivos), como las documentadas en los santuarios de Collado de los Jardines y la Cueva de la Lobera (Lantier 1917; Calvo y Cabré 1919). La superficie muestreada abarcó una hectárea (Fig. 3). Las zonas con ciertas anomalías fueron contrastadas mediante catorce sondeos arqueológicos, localizados donde había material arqueológico en superficie o donde los indicadores geomorfológicos inducían a pensar en la existencia de evidencias estructurales. Los resultados siempre fueron negativos. El resultado común de las prospecciones superficial y geofísica y de la batería de sondeos mencionadas fue la ausencia de estructuras y estratigrafía. Ello apuntaba a una configuración original del sitio como lugar de culto al aire libre donde se realizaron actividades rituales y se depositaron ofrendas.

Como el registro era fundamentalmente metálico y no estratificado, ha sido básica una aproximación superficial de carácter integrado. La microprospección arqueológica superficial y el seguimiento de los mo- 


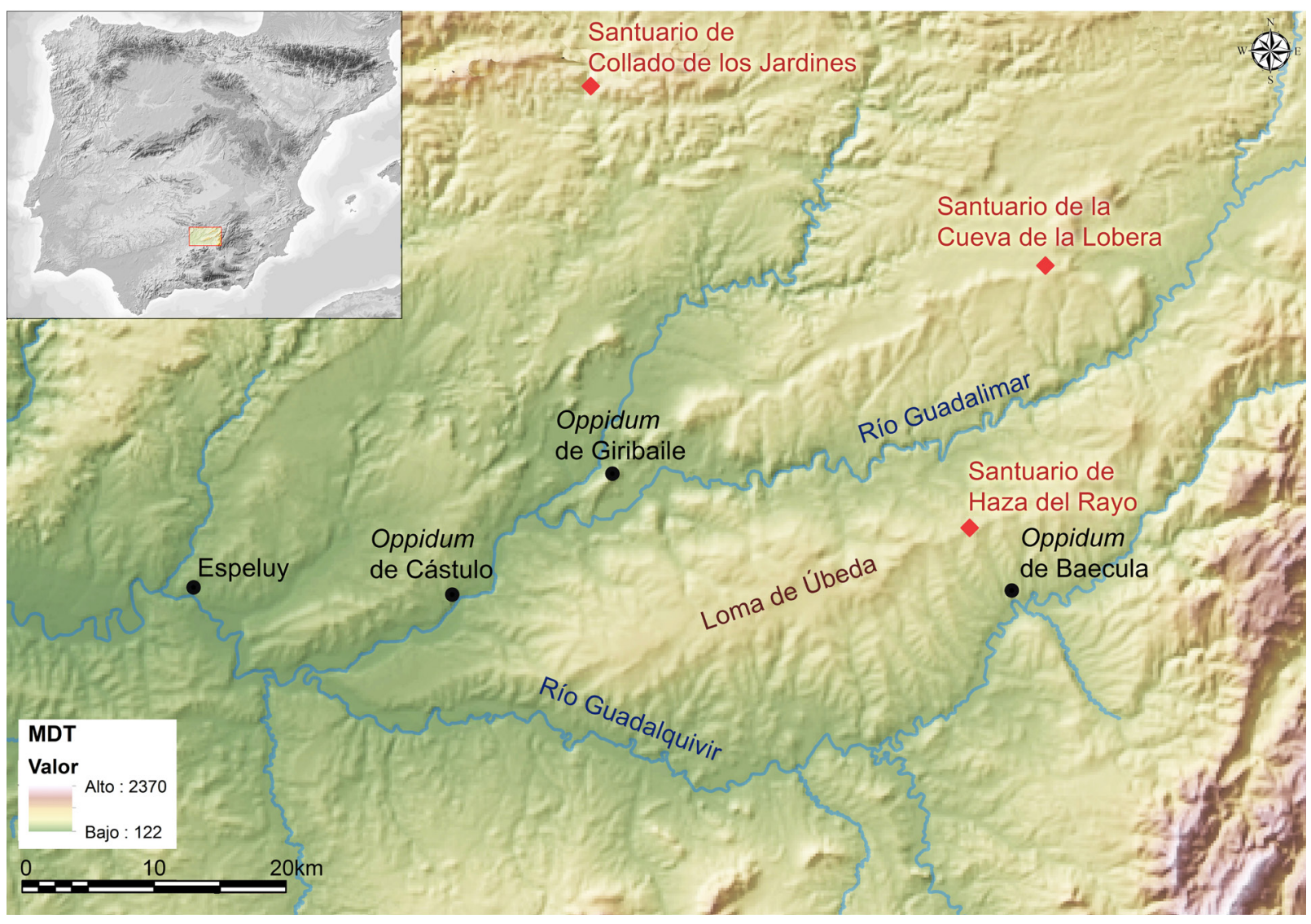

Fig. 1. Localización del santuario de Haza del Rayo en la península ibérica y en el territorio de Cástulo (Jaén). Modelo digital de superficie MDT05, Centro Nacional de Información Geográfica (http://centrodedescargas.cnig.es/CentroDescargas/index.jsp). En color en la edición electrónica.

vimientos de tierra resultaron fundamentales, siempre apoyados por el uso del detector de metales y de GPS de alta precisión para la georreferenciación. Esta metodología de trabajo ya se había mostrado muy eficaz en otros casos, como los escenarios bélicos del Alto Guadalquivir, donde la prospección geomagnética con detector se había usado sistemáticamente. Los lugares de culto al aire libre y estos escenarios serían difícilmente localizables a través de la mera prospección superficial. Por ello el detector de metales debería incluirse como una herramienta más, usado de forma controlada y dentro de una batería metodológica adecuada, siempre bajo control y determinando la afección a la estratigrafía o contextos conservados (Bellón et al. 2020).

El sistema de registro, por tanto, ha seguido pautas similares a las de trabajos previos en el desarrollo del método y la documentación de materiales. Se cuenta así con una base analítica importante para la generación de interpretaciones que se sustenta en el uso de cartografía de detalle donde todo el material se ubica con precisión centimétrica. El registro ha sido exhaustivo gracias a la articulación de técnicas diversas y complementarias, como la microprospección magnética y la cartografía específica mediante vuelo con dron equipado con sensores de detección por luz y distancia (LIDAR). Se ha muestreado el $100 \%$ de la superficie, delimitando la dispersión del depósito y rasgos específicos de su distribución. Los resultados documentan un corpus de materiales que definen con contundencia este sitio como un lugar de culto. Destacan un conjunto de exvotos, ofrendas y otros objetos rituales. Por otra parte, el diseño metodológico ha permitido evaluar el impacto del proceso de expolio sufrido y evitar su continuidad con una cobertura sistemática del área afectada (Fig. 3).

Asimismo, el seguimiento de la limpieza superficial mecánica de la traza de autovía ha definido un área específica, localizada en la vaguada al suroeste de la dispersión de materiales, caracterizada por la acumulación de arcillas de color oscuro. El inicio de esta unidad coincidía con el límite de la distribución del material arqueológico. Las actuaciones se han orientado a documentar, en su caso, huellas de interés arqueológi- 

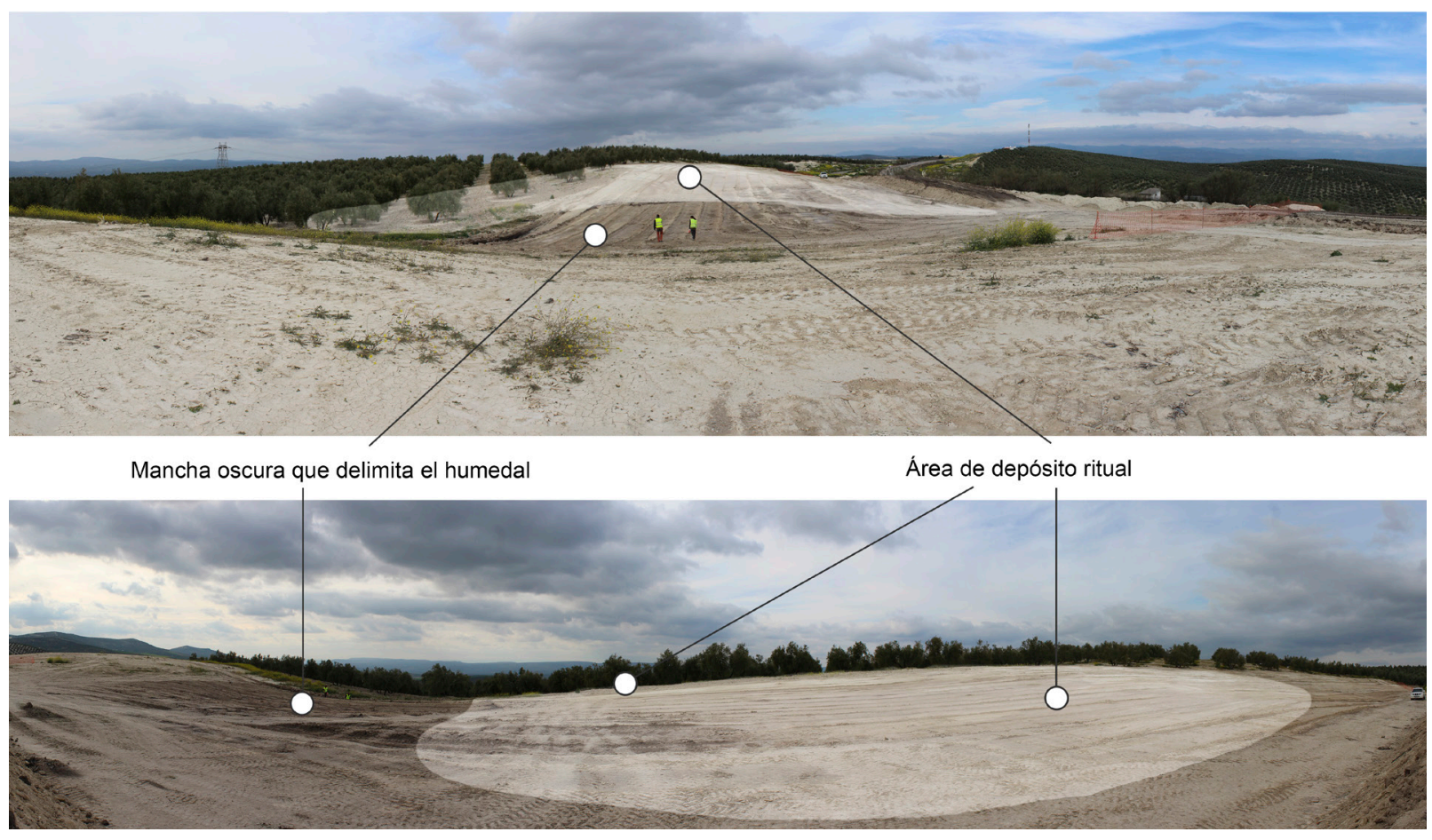

Fig. 2. Vistas panorámicas del santuario de Haza del Rayo, con indicación de sus principales áreas funcionales. En color en la edición electrónica.

co no perceptibles superficialmente, así como a desarrollar un muestreo estratigráfico de sedimentos para su análisis micromorfológico, geoquímico y arqueobotánico. Un muestreo superficial de cobertura total se combinó con dos trincheras de excavación arqueológica. Pronto se constató que las arcillas con perfil en artesa eran arqueológicamente estériles, lo que situaba la distribución del material votivo siempre al exterior de las mismas.

Los resultados obtenidos en ese espacio se consideraron fundamentales. Se consiguieron integrando un estudio geoarqueológico de alta resolución con análisis de fitolitos y polínicos sobre muestras de sedimento y con datación por luminiscencia ópticamente estimulada (OSL por sus siglas en inglés). Estos últimos (OSL) están en curso. La estrategia metodológica multiproxy diseñada combina métodos y técnicas que operan a alta resolución en una escala microscópica de análisis, partiendo de la micromorfología de suelos y sedimentos. $\mathrm{Su}$ fin es identificar facies, caracterizar estructuras y componentes sedimentarios y localizar de modo detallado los microrrestos para entender los procesos deposicionales y postdeposicionales que se demuestran indispensables para su interpretación. Esta aproximación interdisciplinar ha contribuido a caracterizar esta zona como un humedal temporal, tal y como detallaremos a continuación.

\section{EL DEPÓSITO VOTIVO}

\subsection{La caracterización del depósito y del humedal temporal}

La definición de un lugar de culto, fuertemente vinculado al ámbito natural, ha sido un reto. Por un lado, había que comprender el significado cultural de unos hitos en el territorio, sin apenas modificaciones antrópicas, que dejaran una huella fosilizada. De otro, había que trabajar con un registro en horizontal, para definir aspectos relacionados con la distribución de las ofrendas. Estas se entendían como un depósito en abierto y no como un atesoramiento concentrado de las mismas, contenidas en estructuras bien definidas. Es un área al aire libre, que aprovecha un punto de paso en la imponente frontera natural que es la Loma de Úbeda. Topográficamente se puede definir como un collado en la divisoria de aguas de los ríos Guadalimar y Guadalquivir, un ámbito de 1,3 ha donde se combinan hitos de gran relevancia. Esto nos lleva a abordar, de manera específica, cómo se incorporan determinados componentes paisajísticos en la planificación de la ritualidad o en la organización de itinerarios, entre otras cuestiones (Elsner y Ruttherford 2005). En Haza del Rayo el humedal temporal pudo potenciar este lugar como punto de atracción, contribuyendo a ordenar y condi- 


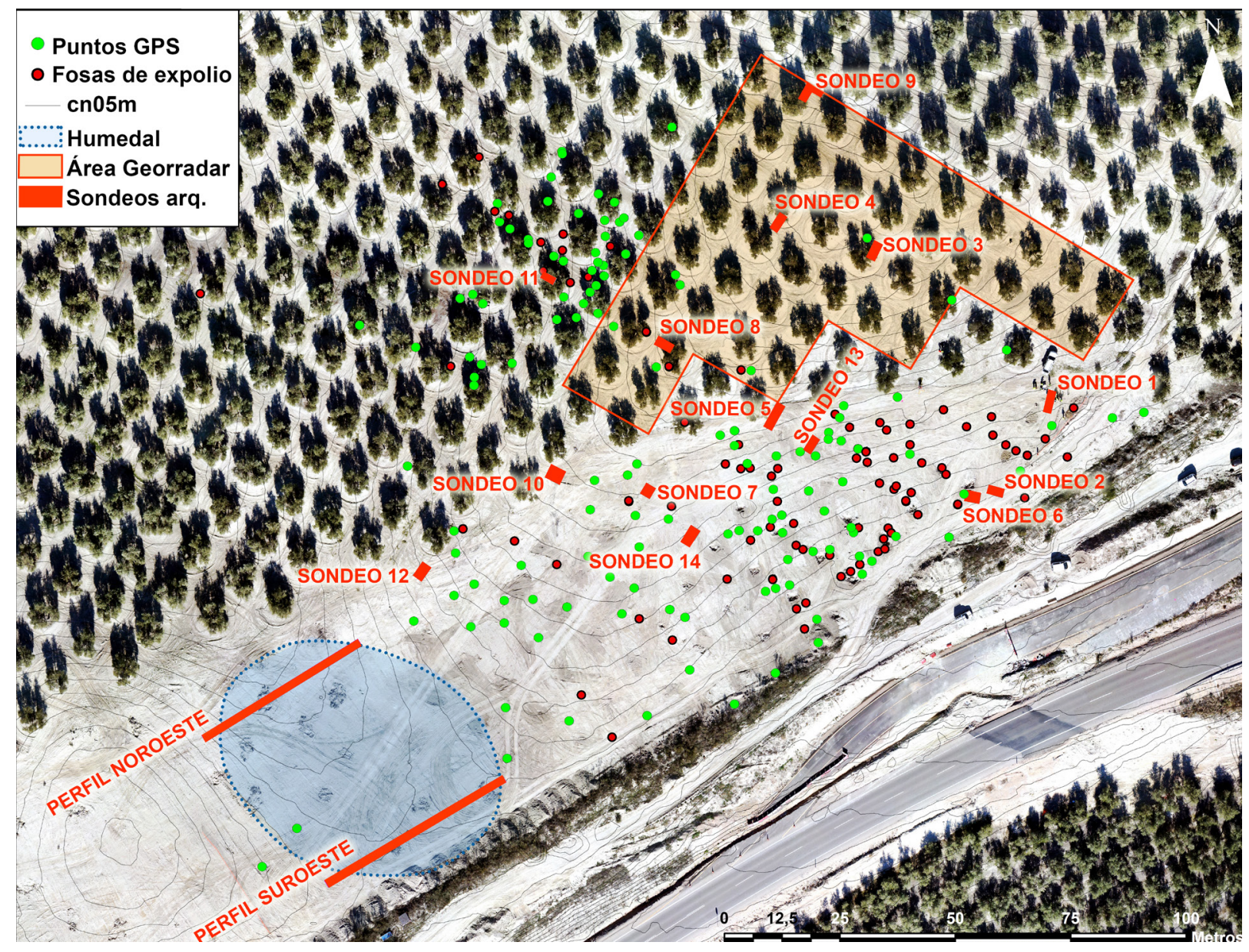

Fig. 3. Ortofotografía digital del paleo-humedal de Haza del Rayo y zona de depósito votivo con la situación de los sondeos arqueológicos, la zona prospectada con georradar, los expolios y la distribución de los materiales documentados con GPS. En color en la edición electrónica.

cionar las formas de tránsito en torno a él. Pudo constituirse como un hito en el territorio inmediato, donde no abundan ecosistemas de este tipo, dotando a este lugar de unos rasgos propios, definitorios, sugerentes para la proyección de esquemas simbólicos. Al tiempo pudo funcionar como un elemento articulador del rito y del depósito de ofrendas, tal y como se aprecia en los modelos de distribución.

Este humedal se localiza en la parte más baja del collado, mientras que las ofrendas se distribuyen exclusivamente en el lado noreste, en las vertientes norte, sur y oeste de una pequeña cota. Como se indicó, nunca se hallaron al interior del mismo. La microprospección arqueológica superficial desarrollada de manera sistemática en todo el perímetro de esta unidad tampoco documentó depósito en la vertiente suroeste del humedal. Conserva $2500 \mathrm{~m}^{2}$, sin que se haya podido precisar su límite sur por estar afectado por la antigua carretera N-322. Se define como una artesa con una estratigrafía bastante homogénea, conformada por el depósito de aportes sedimentarios arcillosos, de tonalidad oscura, con una potencia máxima de aproximadamente $1,50 \mathrm{~m}$, que han sido caracterizados mediante micromorfología (Stoops 2003). El depósito oscuro identificado en Haza del Rayo corresponde a un paleosuelo desarrollado sobre unas margas grises del Mioceno (Fig. 4). Su color se debe a la destacada presencia de materia orgánica humificada y a la movilidad de los cationes de la arcilla por su posición fisiográfica en el paisaje, en una depresión entre dos lomas. Los rasgos de este paleosuelo son compatibles con la presencia de agua y la colonización de plantas con una intensa actividad microbiana, en concreto, con una saturación de agua (iestacional?) seguida de momentos alternantes de desecación. Los excrementos de mesofauna del suelo indican episodios de exposición subaérea y colonización por parte de esa fauna entre períodos de encharcamiento. Los resultados de los análisis de microrrestos vegetales son 


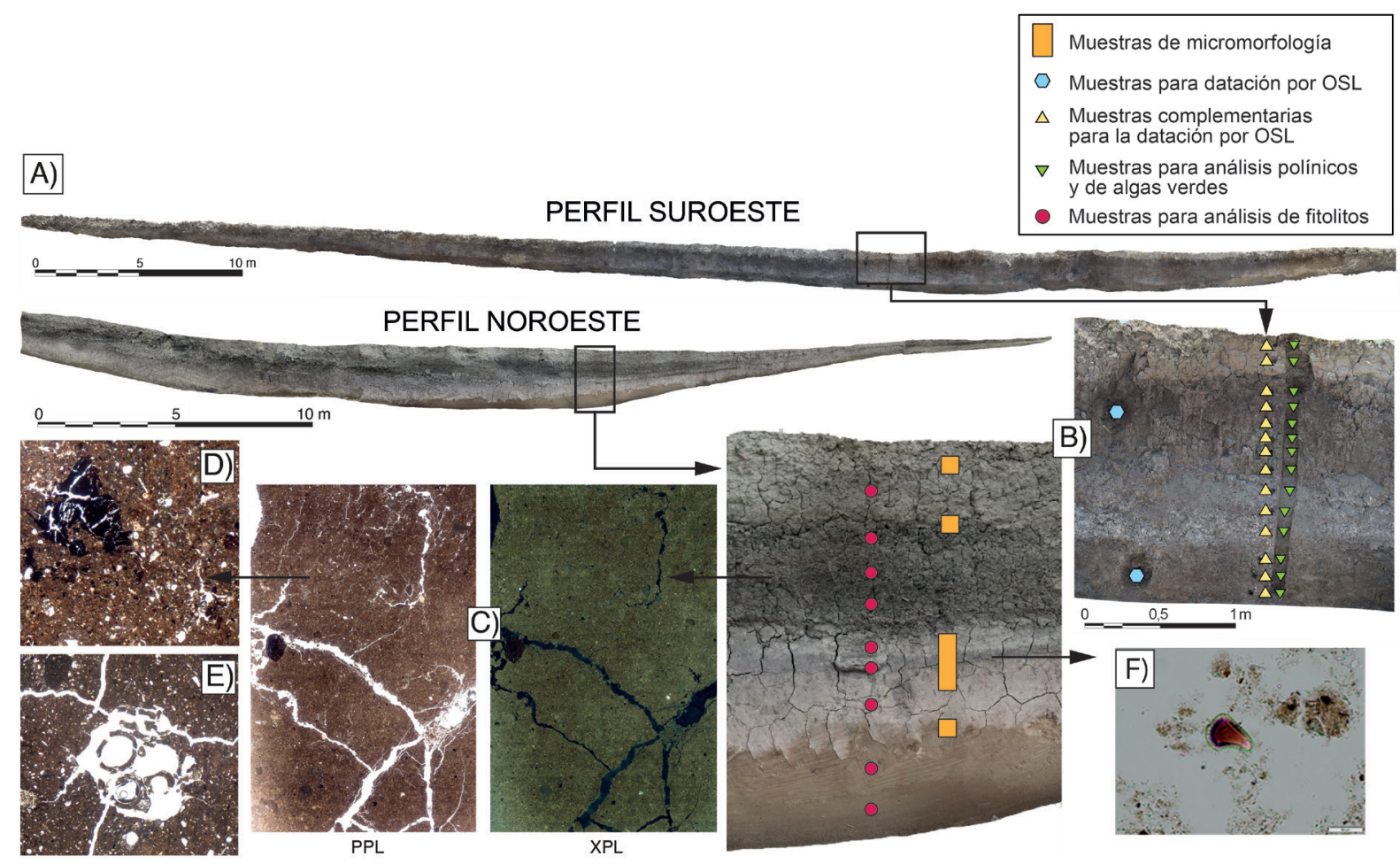

Fig. 4. Caracterización de los depósitos del paleo-humedal de Haza del Rayo (Sabiote, Jaén): A. Perfil estratigráfico; B. Detalle de la secuencia estratigráfica; C. Lámina delgada de la muestra 3 de paleosuelo (PPL: Luz polarizada plana; XPL: Luz polarizada cruzada); D. Microfotografía de microcarbones y materia orgánica humificada conservando su estructura celular; E. Microfotografía de excrementos de mesofauna; F. Microfotografía de fitolito del paleosuelo, célula buliforme de hojas de gramíneas; OSL luminiscencia ópticamente estimulada (por sus siglas en inglés). En color en la edición electrónica.

con la presencia de un paleo-humedal, contribuyendo a su caracterización. Los fitolitos indican una composición vegetal en cierta manera homogénea durante la secuencia deposicional. Está dominada por gramíneas de la subfamilia Pooideae, que son comunes en medios húmedos. Esas concentraciones de poáceas, así como de hojas de arecáceas (palmáceas), se encuentran especialmente en el paleosuelo. A su vez la aparición de biomicrofósiles silíceos, como diatomeas y espículas de esponja, es característica de ecosistemas acuáticos o de ambientes húmedos (Coil et al. 2003).

\subsection{Los exvotos en bronce}

Las actuaciones desarrolladas han recuperado un corpus de material homogéneo, vinculable a un uso ritual, salvo elementos, como las tachuelas, asociadas a la utilización de este paso natural a partir de finales del siglo III a. n. e. Predomina la ofrenda metálica. La categoría votiva principal son los exvotos en bronce, única iconografía en este santuario y material fundamental para inferir aspectos relacionados con el ritual (Nicolini 1969; Prados 1992; Prados et al. 2018; Rueda 2008).

Resaltamos, de nuevo, el valor de la aproximación a un registro inédito, que nos brinda la posibilidad de mirar a este tipo de ofrendas desde otras perspectivas, como material que se incorpora a contextos tipológicamente diferentes. El propio contexto del hallazgo ha llevado a que, junto al análisis tipológico e iconográfico, se haya planificado otro metalográfico encaminado a determinar aspectos de autenticidad, así como la composición de los bronces ${ }^{3}$.

Hemos documentado más de cincuenta exvotos en bronce. Algunos están completos, pero predominan los fragmentos (Fig. 5). Es interesante que algunas de las piezas están fragmentadas de antiguo mediante doblado o roturas intencionadas con retoques evidentes

\footnotetext{
3 Ignacio Montero ha analizado 4 piezas en el Laboratorio de Arqueometría de Materiales (LAM) del Instituto de Historia (CSIC). Los resultados apuntan a la autenticidad de las piezas y proporcionan datos referentes a su composición y a la procedencia del plomo utilizado (isótopos de plomo). Esta sería el distrito de Linares y, en algunos casos, minas de plomo que podrían ser de la provincia de Murcia (Cartagena-Mazarrón).
} 


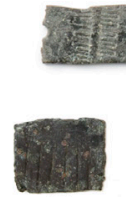

(99)

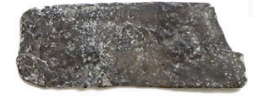

(206)

(3)

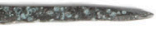

(11)

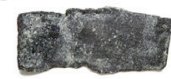

(83)

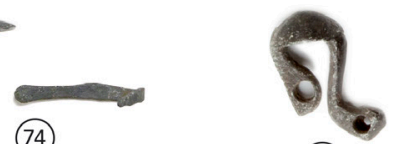

(74)

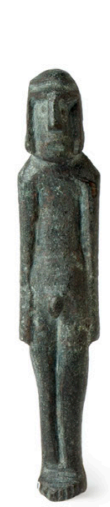

(9)

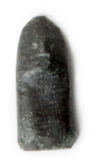

(4)

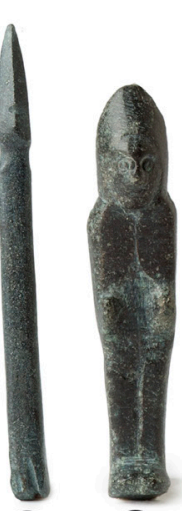

(5)

(95)

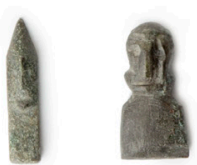

(53) (57)

(93)

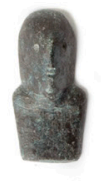

(17)

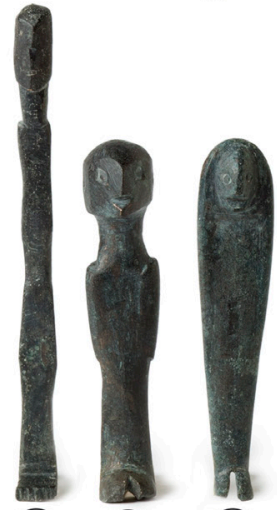

(103)

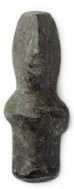

(94)

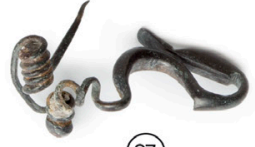

(97)

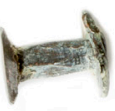

(72)

(15)

(25)

(152)

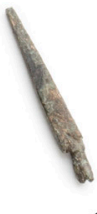

(127)

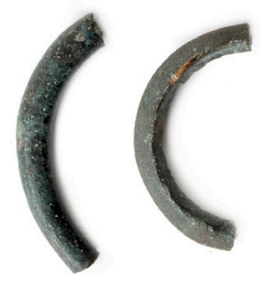

(89)

(133)

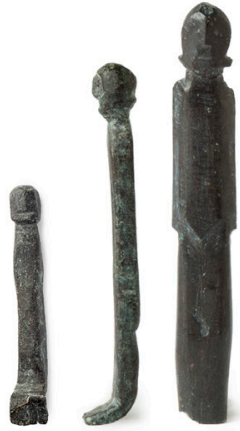

(35) (32)

(84)

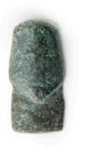

(105)

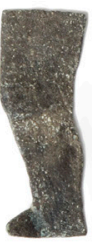

(33)
(124)

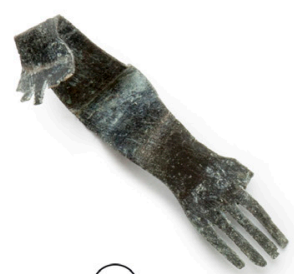

\section{$0 \quad 1 \mathrm{~cm}$ \\ m}

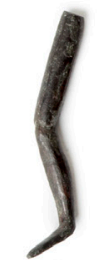

(125)

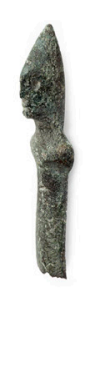

(90) (154)
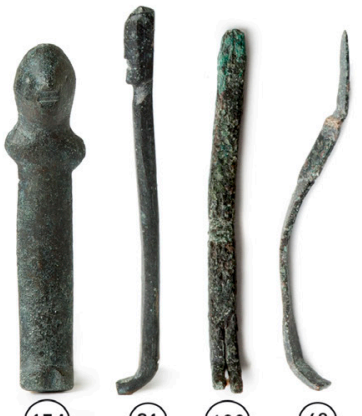

(60)
(85)

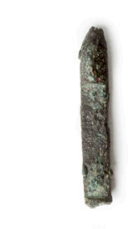

(128)
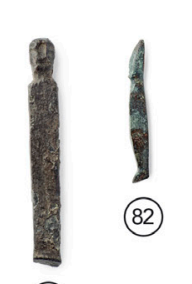

(91)

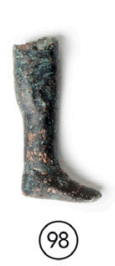

(80)

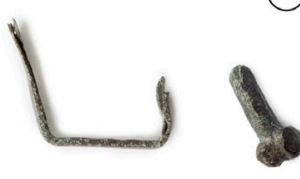

(51)

(69)

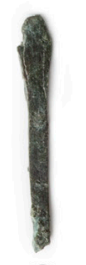

Fig. 5. Selección del material documentado en el depósito votivo de Haza del Rayo con indicación del número de identificación SIG. En color en la edición electrónica.

Trab. Prehist., 78, N. ${ }^{\circ}$ 1, enero-junio 2021, pp. 140-152, ISSN: 0082-5638

https://doi.org/10.3989/tp.2021.12269 
(Fig. 5: 4 y 105). Esta idea, apenas esbozada porque requiere de una reflexión mayor, apunta a las claves que ofrece este santuario para aproximarnos a los procedimientos rituales.

En general, no hay un predominio destacable en los exvotos entre los masculinos y los femeninos. Todos tienden al semi-esquematismo y esquematismo. Los modelos entran dentro de las tipologías más comunes para el territorio de Cástulo y, de manera específica, en la órbita estilística e iconográfica del santuario de Castellar (Nicolini et al. 2004: 169-171). El análisis de las tipologías rituales, en base a la muestra documentada, no permite afirmar que nos encontremos ante un lugar de culto con una dedicación determinada. Sí es interesante indicar que en este corpus faltan categorías asociadas a los ritos de paso o nupciales, así como imágenes de hombres con armas, rituales que debieron sancionarse en los santuarios centrales. El santuario de Haza del Rayo corrobora la idea que ya hemos apuntado (Ruiz y Rueda 2014: 141): existen espacios de culto complementarios, articulados en red y vinculados o no a la ciudad, donde el ritual se relaciona con peticiones enmarcadas en la esfera del reconocimiento social.

Un aspecto específico es la producción de imagen figurativa sobre lámina recortada. Un ejemplar excepcional representa parte de una imagen femenina de perfil de finos rasgos faciales, recortada en una fina placa de bronce (Fig. 5: 85). Su rasgo definidor es la presencia de una estilizada tiara apuntada, uno de los atributos característicos del atuendo femenino. En este contexto valoramos el conjunto de plaquitas/láminas en bronce documentadas, algunas decoradas (Fig. 5: 11, 99, $83,206)$. Pueden tratarse de ofrendas específicas, así como de partes de exvotos, que también constatamos en bronce, plata y oro en Castellar y Despeñaperros (Rueda 2011: 107-109).

Los exvotos anatómicos (Fig. 5: 124, 33, 125, 98, $80,51,69)$ conforman otro conjunto interesante. Presentes en distintos santuarios peninsulares, destacan por su heterogeneidad en los de Cástulo y, sobre todo, en Despeñaperros (Prados 1991). En el pequeño corpus de Haza del Rayo se adscriben a tres categorías: piernas, falos y brazos-manos, destacando una pieza con dos brazos unidos y manos abiertas. El depósito de ofrendas en el humedal puede vincularse al universo de la protección y la curación, pero también de la propiciación, donde el agua jugaría un papel activo y determinante (Sánchez del Moral 2018).

\subsection{Otras ofrendas metálicas}

Las fíbulas están representadas en Haza del Rayo por cuatro ejemplares parciales de fíbulas anulares, junto a una fíbula La Tène bien conservada. En su mayoría son de pequeñas dimensiones (Fig. 5: 17, 97), un rasgo común en algunos de los depósitos rituales conocidos en el Alto Guadalquivir (Rueda 2011). La asociación de fíbulas y exvotos de bronce en contextos rituales se conoce, p. ej., en los santuarios de Collado de los Jardines y la Cueva de la Lobera. Allí las fíbulas son los segundos objetos más frecuentes, posiblemente asociados a la ofrenda de prendas, mantos y túnicas (Izquierdo 2001).

Otro conjunto variado de ofrendas e instrumental ritual en bronce son los aros (Fig. 5: 89, 133) y elementos metálicos no identificados (EMNI) de difícil interpretación, algunos de los cuales reiteran claros patrones formales (Fig. 5: 15, 25, 152). También hay alguna miniatura, como una posible punta de lanza (Fig. 5: 127) o una aguja (Fig. 5: 3) que, aunque no son abundantes, aparecen en diferentes contextos rituales y de representación social (López-Bertran y VivesFerrándiz 2015).

\subsection{La cerámica votiva}

Junto a este corpus votivo se halló un conjunto cerámico, muy escaso y fragmentario, que no ha permitido una ordenación tipológica en profundidad, pero sí orientativa. A priori, las tendencias formales remiten a un horizonte del siglo IV-III a. n. e. Predominan formas abiertas, como platos, en pequeño tamaño, y otras cerradas de borde recto (Fig. 6), así como la cerámica clara decorada. La aparición puntual de algún ejemplar de cerámica gris decorada en rojo es otro indicio de que el santuario de Haza del Rayo se inscribe en la órbita de Cástulo, vinculándose a producciones exclusivas de este territorio ${ }^{4}$. Un rasgo que caracteriza, de forma global, al conjunto es la predominancia de una cerámica de mesa, de reducido tamaño. Ese condicionante funcional se relaciona posiblemente con producciones de exclusiva utilización ritual.

\subsection{Algunos aspectos espaciales y cronológicos}

Nos encontramos ante un depósito votivo que es consecuencia de una frecuentación recurrente lo que nos conduce a interpretarlo como un santuario al aire libre, identificado en el territorio circundante a partir de los hitos naturales ya indicados. En el espacio religioso ibero $\mathrm{y}$, en concreto, en el área bastetana (Adroher et al. 2004; Adroher y Caballero 2008), ya se han analiza-

\footnotetext{
${ }^{4}$ M. ${ }^{a}$ I. Moreno. Decoración vascular y significación social en los territorios iberos. Los estilos y grupos pictóricos de la cerámica a torno del Alto Guadalquivir (ss. VI a. n. e.-I d. n. e.). Tesis doctoral inédita, Universidad de Jaén, 2019.
} 

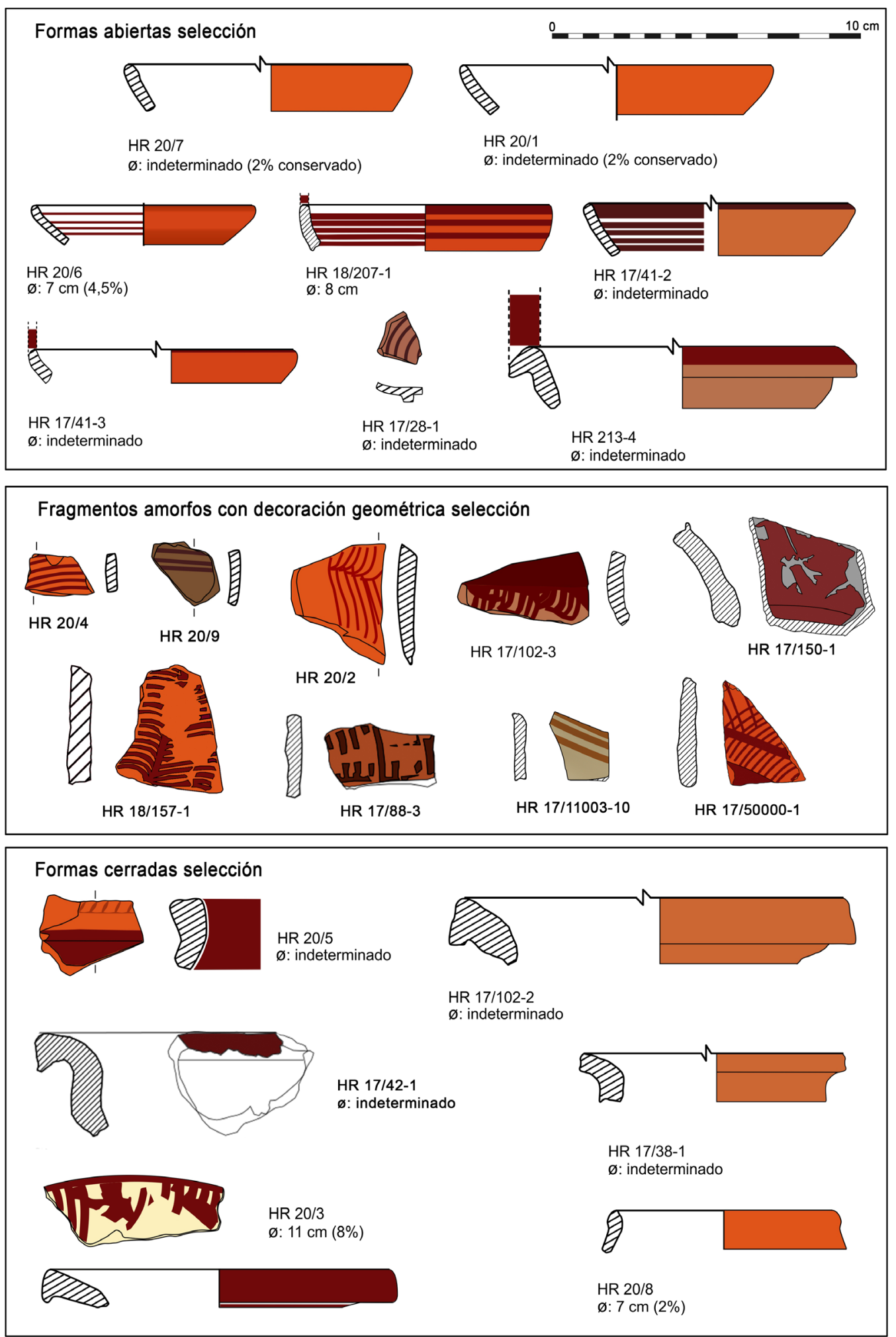

Fig. 6. Selección del material cerámico documentado en el depósito votivo de Haza del Rayo. En color en la edición electrónica. 
do estos santuarios al aire libre, con rasgos espaciales y contextuales concretos. La regularidad del registro y las dinámicas espaciales en Haza del Rayo nos acercan a algunos aspectos distributivos y organizativos del santuario, aunque las alteraciones producidas por el expolio han afectado en parte la composición cualitativa y cuantitativa de sus contextos, condicionando nuestra aproximación a aspectos como la propia escala de participación.

Las diferentes categorías votivas siguen patrones espaciales similares sin apreciarse dinámicas específicas, ni complementarias. La interrupción de la distribución de la cerámica en la zona de limos permite pensar que responde a los mismos criterios rituales que el resto de ofrendas. Tampoco las clases de ofrendas o los tipos rituales de la toréutica se concentran de modo perceptible. Los exvotos en bronce se distribuyen en todas las áreas sea cual sea su tipo iconográfico y/o ritual. De manera puntual hemos constatado la disposición de exvotos en las margas arcillosas, probablemente en pequeñas fosas de depósito, sin poder preci- sar que se trate de una dinámica homogénea en todo el depósito (Fig. 7).

El culto en este lugar se fecha entre los siglos IV-III a. n. e. y, en concreto, en el siglo III a. n. e., momento de mayor apogeo de los santuarios de Cástulo y de integración de la ciudad de Baecula en su órbita política (Ruiz y Rueda 2014). El uso ritual no va más allá de inicios del siglo II a. n. e. Faltan aquí las evidencias materiales y/o contextuales que sí se aprecian en los santuarios supra-territoriales, como las reestructuraciones espaciales, vinculadas a la presencia de cerámica romana o de iconografía hispano-romana en terracota (Rueda y Ruiz 2017: 171-172).

La determinación de la larga diacronía y formación del paleo-humedal aún está en curso ${ }^{5}$. De momento planteamos la hipótesis de que abarcó una parte significativa del Holoceno tardío, incluyendo el período ibero, dado que el depósito de ofrendas nunca traspasa los

\footnotetext{
5 Quizás la datación por luminiscencia ópticamente estimulada (OSL por sus siglas en inglés) nos ayude a precisar mejor estos aspectos.
}

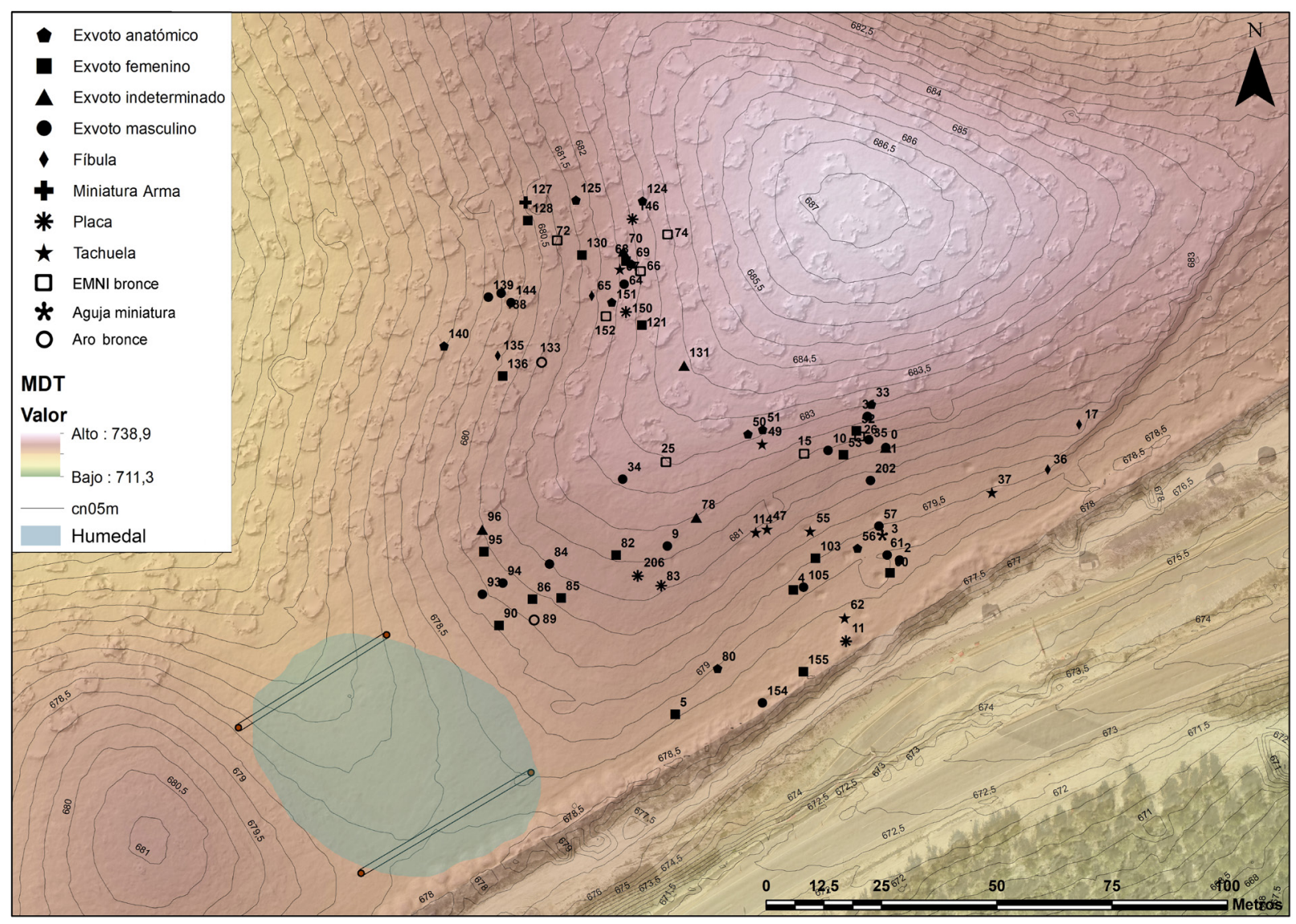

Fig. 7. Modelo digital del terreno del paleo-humedal de Haza del Rayo y zona de depósito votivo con la distribución de las ofrendas metálicas, diferenciadas por categorías. En color en la edición electrónica. 
límites del paleo-humedal y está delimitado en planta y secciones por la extensión del paleosuelo.

\section{LA MEMORIA RITUAL IMPRESA EN EL PAISAJE}

Con los datos disponibles hasta el momento, interpretamos el santuario de Haza del Rayo como la sacralización de un paso, una etapa en el itinerario ritual hacia el santuario de Castellar. Su condición de hito y referencia paisajística, indudablemente estaría relacionada con el corredor natural y potenciada por el humedal temporal y el agua, de presencia intermitente. Estos 'rasgos excepcionales' (físicos, visuales, espaciales, etc.) son muy sugerentes para su integración en el culto (Whitehouse 1992).

Como en Haza del Rayo, en el territorio de Cástulo es posible analizar cómo la movilidad ritual y determinadas etapas en el paisaje forman parte importante de las dinámicas rituales. El acceso a los santuarios supraterritoriales de Collado de los Jardines y la Cueva de la Lobera, muy distantes de los centros habitados (a más de $40 \mathrm{~km}$ de Cástulo), requiere emprender un viaje que supera la escala regional. En algunas ocasiones debió tener claras connotaciones de iniciación y superación (Morinis 1992; Grau y Amorós 2013), además de implicar estrategias e infraestructuras para la consecución de estas peregrinaciones (Nordin 2009; López-Bertran 2011: 91-92; Machause 2020: 191-198) (Fig. 8).

En este contexto, contraponer estos santuarios centrales con los lugares de culto, intermedios o complementarios como Haza del Rayo, nos aproxima también a la reconstrucción de los paisajes sagrados en este antiguo territorio. En estas lecturas adquieren un rol fundamental los ámbitos definidos como "regiones simbólicas marginales". Situados fuera de los grandes centros religiosos, representan una expresión básica de interacción social (Larsson 2006: 80), que destaca el papel del paisaje como agente activo y funcional (Bradley 2000), fundamental para la comprensión de las dinámicas y de las conexiones que se generan a través del ritual (Palka 2014: 8-9).

La complejidad y jerarquización de estos paisajes rituales se acentúan a medida que avanzamos en los métodos de análisis y de documentación de sus huellas, sobre todo si poseen un menor grado de alteración antrópica, como puede ser el caso analizado. En concreto nos referimos a lugares de ubicación selectiva y de visita recurrente, donde cabe determinar la acción de prácticas de carácter cíclico que favorecen una memoria cultural, fundamental para la transmisión de las creencias. Haza del Rayo pone de manifiesto una forma particular, no documentada antes para el Alto Guadalquivir, de la utilización del paisaje a través del
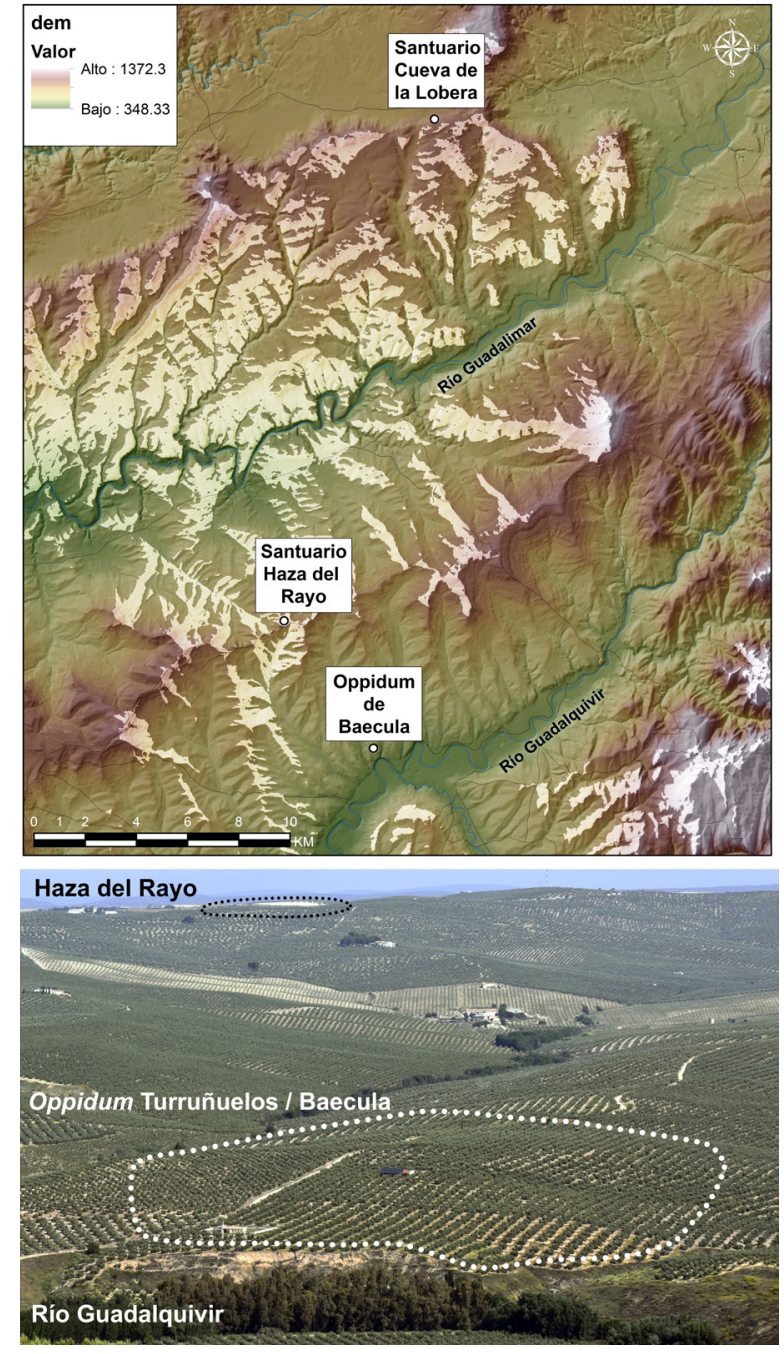

Fig. 8. Arriba: mapa de visibilidad acumulada a escala regional desde Haza del Rayo. Puntos de observación 240. Altura del Visor (Offseta 1.7). Cálculo realizado sobre MDT05 (CNIGPNOA). Santuario supra-territorial $\rightarrow$ Cueva de la Lobera; Santuario de paso $\rightarrow$ Haza del Rayo; Oppidum $\rightarrow$ Baecula. Modelo digital de superficie MDT05, Centro Nacional de Información Geográfica (http://centrodedescargas.cnig.es/CentroDescargas/index.jsp). Abajo: vista panorámica del oppidum de Baecula y del santuario de Haza del Rayo. En color en la edición electrónica.

depósito de objetos y de su interacción específica con hitos, como el humedal o el corredor natural, que pudieron ser una condición para el ritual. El primero de los aspectos específicos que lo definen es el carácter colectivo y comunitario del ritual documentado, cuyo sentido y coherencia se logra incorporando imágenes y ofrendas que responden a solicitudes diversas y complementarias. En concreto, la iconografía de Haza del Rayo remite a prácticas de agregación, a ritos de protección y salud, así como a rituales de iniciación, 
que delinean -entre otras cuestiones- formas de acceso al territorio. A través de estas ofrendas, por tanto, los principios de percepción cultural se enmarcan en la concepción de permiso, salud y protección vinculados al propio viaje ritual. Están ligados a las fronteras transicionales, como marcadores rituales de esos espacios liminares donde lo sobrenatural adquiere una dimensión tangible, como se ha advertido por ejemplo en las apachetas andinas (Galdames 1990).

El segundo aspecto definitorio de Haza del Rayo es la propia lógica espacial del depósito, que refleja normas que se repiten y respetan. Entre ellas está la exclusión de ofrendas en el humedal o la intención de potenciar el carácter (sobre)natural de este lugar, a través de significarlo y ritualizarlo sin modificaciones antrópicas de impacto.

La aproximación desde el territorio político permite, además, contextualizar dinámicas a distintas escalas y desde una perspectiva diacrónica. En este caso se enmarcan en la definición del territorio de Cástulo que, para el siglo III a. n. e., se organiza como una estructura piramidal jerarquizada de oppida (Ruiz et al. 2013). En este proceso y con el fin de la Segunda Guerra Púnica este territorio es objeto de fuertes transformaciones. Sus principales ciudades son abandonadas y/o destruidas, mientras que sus santuarios sobreviven con una estructura ritual diferente (Rueda y Ruiz 2017). La geografía sagrada sucumbe a las fuerzas de los cambios a escala global. Se abandonan lugares como Haza del Rayo, se interrumpe el culto en el humedal y, aunque posiblemente este hito siguió visible, pierde gran parte de su sentido original, al igual que poco a poco lo irán perdiendo otros referentes territoriales, como la propia Cueva de la Lobera. El corredor natural de Haza del Rayo parece que siguió activo puntualmente, ya que la presencia de tachuelas indica ese uso, aunque en una frecuencia muy baja, transformando su función originaria frente a la nueva reorganización del territorio, que se produce fundamentalmente desde mediados del siglo II a. n. e.

\section{AGRADECIMIENTOS}

En el desarrollo de esta actuación ha sido clave la implicación ciudadana, de donde partió la voz de alarma, la diligencia de la Delegación Territorial de Cultura en Jaén, así como la plena cooperación por parte de la empresa encargada de la ejecución de la obra. Destacamos la amplia colaboración de investigadoras e investigadores de diversas instituciones que muestra la gran potencialidad futura de esta investigación: Jorge Delgado, José Luis Pérez y José Miguel Gómez, del Grupo de Investigación Sistemas Fotogramétricos y Topométricos (TEP-213) de la Universidad de Jaén; José A.
Peña del Instituto Universitario de Investigación Andaluz de Geofísica-Universidad de Granada; Francisca Alba, del Dpto. de Biología de la Universidad de Granada; Ignacio Montero del Instituto de Historia (CSIC) y Jorge Sanjurjo Sánchez del Instituto Universitario de Xeoloxía Isidro Parga Pondal, Universidade da Coruña. Francisco Guerrero y Fernando Ortega del Dpto. de Biología Animal, Biología Vegetal y Ecología de la Universidad de Jaén nos aportaron sugerencias a la definición de este espacio. Mario Gutiérrez Rodríguez es Honorary Visiting Research Fellow en la School of Archaeology and Ancient History, University of Leicester, donde ha realizado parte de esta investigación gracias a un contrato postdoctoral financiado por el Programa de Perfeccionamiento de Doctores del Plan Propio de Investigación de la Universidad de Granada.

\section{BIBLIOGRAFÍA}

Adroher, A. y Caballero, A. 2008: "Los santuarios al aire libre en el entorno de Basti (Baza, Granada)". En A. Adroher y J. Blánquez (eds.): $1^{\text {er }}$ Congreso Internacional de Arqueología Ibérica Bastetana (Baza 2008) II: 215-228. Madrid.

Adroher, A.; Sánchez, A. y Caballero, A. 2004: "Los espacios rituales ibéricos". En A. Adroher y A. M. López (eds.): El territorio en las altiplanicies granadinas entre la prehistoria y la Edad Media. Arqueología en la Puebla de Don Fadrique (1995-2002). Arqueología Monografías 20, Junta de Andalucía, Consejería de Cultura. Sevilla: 185-218.

Bellón, J. P.; Rueda, C.; Lechuga, M. A.; Ruiz, A.; Molinos, M. y More-

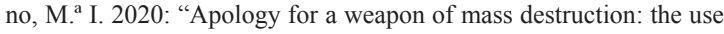
of the metal detector in archaeology. Research and management experiences in the Alto Guadalquivir región". Revista d'Arqueologia de Ponent 30: 67-88.

Bellón, J. P.; Ruiz, A.; Molinos, M.; Rueda, C. y Gómez, F. (eds.) 2015 : La Segunda Guerra Púnica en la Península Ibérica. Baecula, arqueología de una batalla. Arqueología Serie Ibera 7. UJA Editorial. Jaén.

Bradley, R. 2000: An archaeology of natural places. Routledge. London.

Calvo, C. y Cabré, J. 1919: Excavaciones en la Cueva y Collado de los Jardines (Santa Elena, Jaén). Campaña de 1918, Memoria 22. Junta Superior de Excavaciones y Antigüedades. Madrid.

Coil, J.; Korstanje M. A.; Archer, S. y Hastorf, C. A. 2003: "Laboratory goals and considerations for multiple microfossil extraction in archaeology". Journal of Archaeological Science 30: 991-1008. https://doi.org/10.1016/s0305-4403(02)00285-6

Elsner, J. y Rutherford, I. (eds.) 2005: Pilgrimage in Greco-Roman and Early Christian antiquity: seeing the gods. Oxford University Press. Oxford.

Galdames, L. 1990: "Apacheta, la ofrenda de piedra". Dialogo Andino 9: $10-25$.

Grau, I. y Amorós, I. 2013: "La delimitación simbólica de los espacios territoriales ibéricos: el culto en el confín y las cuevas-santuario". En C. Rísquez, y C. Rueda (eds.): Santuarios Iberos: territorio, ritualidad y memoria. Actas del Congreso El santuario de La Cueva de la Lobera de Castellar 1912-2012 (Jaén 2012): 183-212. Jaén

Grau, I. y Rueda, C. 2018: "La religión en las sociedades iberas: una visión panorámica". Revista de historiografia 28: 47-72. https://doi.org/10.20318/revhisto.2018.4207

Izquierdo, I. 2001: "La trama del tejido y el vestido femenino en la cultura ibérica". En M. Marín (ed.): Tejer y vestir: de la antigüedad al Islam. Estudios Árabes e Islámicos, Monografías I. CSIC. Madrid: 287-311. 
Lantier, R. 1917: El Santuario ibérico de Castellar de Santisteban. Comisión de Investigaciones Paleontológicas y Prehistóricas 15. Junta para la Ampliación de Estudios e Investigaciones Científicas. Madrid.

Larsson, L. 2006: "The ritual use of wetlands during the Neolithic: a local study in Southernmost Sweden". En M. Lillie y S. Ellis (eds.): Wetland archaeology and environments: regional issues, global perspectives. Oxbow Books. Oxford: 79-90.

Livarda, A.; Madgwick, R. y Riera Mora, S. 2018: The bioarchaeology of ritual religion. Oxbow Books. Oxford.

López-Bertran, M. 2011: "Practical movements: kinetic rituals in the Ancient Western Mediterranean". Journal of Mediterranean Archaeology 24 (1): 85-109. https://doi.org/10.1558/jmea.v24i1.85

López-Bertran, M. y Vives-Ferrándiz, J. 2015: "Miniatures from domestic context in Iron Age Iberia". World Archaeology 47 (1): 80-93. https://doi.org/10.1080/00438243.2014.991804

Machause, S. 2020: Las cuevas como espacios rituales en época ibérica. Los casos de Kelin, Edeta y Arse. Arqueologías. Serie Ibera. UJA Editorial. Jaén.

Morinis, A. (ed.) 1992: Sacred journeys: the anthropology of pilgrimage. Greenwood Press. Wesport. Londres.

Nicolini, G. 1969: Les bronzes figurés des sanctuaires ibériques. Presses Universitaires de France. Paris.

Nicolini, G.; Rísquez, C.; Ruiz, A. y Zafra, N. 2004: El santuario ibérico de Castellar, Jaén. Intervenciones arqueológicas 1966-1991. Arqueología Monografías. Junta de Andalucía. Sevilla.

Nordin, A. 2009: "Ritual agency, substance transfer and the making of supernatural immediacy in pilgrim journeys". Journal of Cognition and Culture 9: 195-223. https://doi.org/10.1163/156770909x12489459066228

Palka, J. W. 2014: Maya pilgrimage to ritual landscapes: insights from archaeology, history and ethnography, University of New Mexico Press. Albuquerque, New Mexico.

Prados, L. 1991: "Los exvotos anatómicos del santuario de Collado de los Jardines (Santa Elena, Jaén)". Trabajos de Prehistoria 48: 313-332. https://doi.org/10.3989/tp.1991.v48.i0.528

Prados, L. 1992: Exvotos ibéricos de bronce del Museo Arqueológico Nacional. Dirección General de los Museos Estatales. Madrid.

Prados, L.; Rueda, C. y Ruiz, A. (eds.) 2018: Bronces ibéricos, una historia por contar. Libro Homenaje al Prof. Gérard Nicolini. Ediciones de la Universidad Autónoma de Madrid-Editorial de la Universidad de Jaén. Madrid.

Rísquez, C.; Rueda, C. y Herranz, A. B. 2018: "El santuario de Castellar: nuevas investigaciones y retos futuros". En L. Prados, C. Rueda y A. Ruiz (Eds.): Bronces ibéricos, una historia por contar. Universidad Autónoma de Madrid-Editorial de la Universidad de Jaén. Madrid: 215-236.

Rueda, C. 2008: “Las imágenes de los santuarios de Cástulo: los exvotos ibéricos en bronce de Collado de los Jardines (Santa Elena) y Los Altos del Sotillo (Castellar)". Palaeohispanica 8: 55-87.

Rueda, C. 2011: Territorio, culto e iconografia en los santuarios iberos del Alto Guadalquivir (ss. IV a. n. e. - I d.n. e). Arqueologías. Serie Ibera 3.UJA Editorial. Jaén.

Rueda, C. y Ruiz, A. 2017: "Modelos cultuales a contraste: estrategias de 'continuidad' en los santuarios territoriales del Alto Guadalquivir (finales del siglo III a. n. e. - finales del I a. n. e.)". En T. Tortosa y S. Ramallo (eds.): El tiempo final de los santuarios ibéricos en los procesos de impacto y consolidación del mundo romano. Anejos de Archivo Español de Arqueología 79. CSIC. Madrid: 161-180.

Ruiz, A. y Rueda, C. 2014: "Los exvotos en bronce de la colección Marsal: oppida y santuarios". En Fondo Arqueológico Ricardo Marsal Monzón. Consejería de Educación, Cultura y Deporte, Junta de Andalucía. Sevilla: 131-144.

Ruiz, A.; Rueda, C.; Bellón, J. P. y Gómez, F. 2013: "El factor ibero en la Batalla de Baecula: los efectos colaterales de la guerra". Cuadernos de Prehistoria y Arqueología de la Universidad de Granada 23: 199-225.

Sánchez del Moral, E. 2018: "El agua en las manifestaciones rituales de los pueblos prerromanos: el mundo Ibérico". En M. J. Peréx y C. Miró (eds.): VBI AQVAE IBI SALVS. Aguas mineromedicinales, termas curativas y culto a las aguas en la Península Ibérica (desde la Protohistoria a la Tardoantigüedad). UNED. Madrid: 43-74.

Stoops, G. 2003: Guidelines for analysis and description of soil and regolith thin sections. Soil Science Society of America Inc. Madison, Wisconsin.

Whitehouse, R. 1992: Underground religion: cult and culture in prehistory Italy. Accordia Research Center, University of London. Londres.

Trab. Prehist., 78, N. ${ }^{\circ}$ 1, enero-junio 2021, pp. 140-152, ISSN: 0082-5638

https://doi.org/10.3989/tp.2021.12269 